\title{
SCIDOC
}

\author{
International Journal of Dentistry and Oral Science (IJDOS) \\ ISSN: 2377-8075
}

\section{Effects of Probiotics on Candida albicans in Oral Cavity of Children with Leukemia during Chemotherapy}

Research Article

Nisa P Biantama ${ }^{1}$, Margaretha Suharsini ${ }^{2}$, Mochammad Fahlevi Rizal ${ }^{3}$

${ }^{1}$ Postgraduate Program, Department of Pediatric Dentistry, Faculty of Dentistry, Universitas Indonesia, Jakarta 10430, Indonesia.

${ }^{2}$ Professor, Department of Pediatric Dentistry, Faculty of Dentistry, Universitas Indonesia, Jakarta 10430, Indonesia.

${ }^{3}$ Lecturer, Department of Pediatric Dentistry, Faculty of Dentistry, Universitas Indonesia, Jakarta 10430, Indonesia.

\section{Abstract}

Introduction: Candida albicans is the leading cause of opportunistic microbial infections in patients with cancer. Acute Lymphocytic Leukemia patients undergoing chemotherapy have high risk of candidiasis due to immunosuppression and weakened epithelial barriers. Systemic antifungal drugs' usage is limited by the greater risk of side effects and developing resistant strains, yet currently available topical antifungal drugs are still considered ineffective for immunosuppressed patients including chemotherapy patients.Several studies provide evidence for the feasibility of probiotic Lactobacillus casei to act as alternative antifungal in various human organ systems.

Objectives: To analyze the effects of probiotics on the number of $C$. albicans in oral cavity of children with leukemia during chemotherapy.

Materials and Methods: Saliva samples were taken from 11 children with leukemia during chemotherapy. Subjects were instructed to do mouth rinse with probiotics contained Lactobacillus casei for 60s, twice daily, over the course of 14 days. Unstimulated saliva samples were collected sequentially at 3 time points (baseline, 7 days, and 14 days). The number of $C$. albicans was quantified by qPCR.

Results: Statiscally significant differences were found between the number of C. albicans at baseline $(494.363+180.737$ CFU/ $\mathrm{ml})$, after 7 days $(276.653+69.903 \mathrm{CFU} / \mathrm{ml})$, and after 14 days $(229.286+50.883 \mathrm{CFU} / \mathrm{ml})$ mouth rinsing with probiotics. Significant lower number was found both after 7 and 14 days rinsing with probiotics $(\mathrm{p}<0.05)$.

Conclusion: Probiotics has reducing effects on the number of $C$. albicans in oral cavity of children with leukemia during chemotherapy.

Keywords: Probiotic; Candida albicans; Candidiasis; Leukemia; Chemotherapy.

\section{Introduction}

Cancer is a leading cause of death in children throughout the world. About 300,000 children aged 0-19 years are diagnosed with cancer each year with leukemia as the most common type [1, 2] Chemotherapy is one of the basic and most widely used treatment modalities for cancer. Paediatric hematologic cancer, specifically acute lymphoblastic leukemia (ALL), was taken as terminal disease several decades ago. Now, it is known that with a course of combination chemotherapy, $75-80 \%$ of children with ALL are cured.[3] Chemotherapy works by giving a group of drugs that can inhibit growth or kill cancer cells. However, all chemotherapeutic drugs are cytotoxic by nature not only to cancer cells but also to normal cells. While damaging cancer cells, chemotherapy also gives damage to cells that divide rapidly under normal circumstances, such as digestive tract lining cells including oral epithelium. $[4,5]$

At present, oral mucositis is considered to be the most severeand most common non-haematological side effect associated with chemotherapy. $[6,7]$ Younger cancer patients who undergo chemotherapy are more at risk of oral mucositis due to the high mitotic rate of oral mucosal epithelial cells. Oral mucositis occur in up to $90 \%$ of chemotherapy patients under 12 years old. [7, 8] Destruction of epithelial barriers, which are the host's first line of defence against microorganisms invasions, will increase the sus-

\section{*Corresponding Author:}

Prof. Dr.drg. Margaretha Suharsini Soetopo, SU., SpKGA(K),

Professor, Department of Pediatric Dentistry, Faculty of Dentistry, Universitas Indonesia, Jakarta 10430, Indonesia.

E-mail: m_suharsini@ui.ac.id

Received: December 29, 2021

Accepted: January 30, 2022

Published: February 25, 2022

Citation: Nisa P Biantama, Margaretha Suharsini, Mochammad Fahlevi Rizal. Effects of Probiotics on Candida albicans in Oral Cavity of Children with Leukemia during Chemotherapy. Int J Dentistry Oral Sci. 2022;9(2):5249-5253. doi: http://dx.doi.org/10.19070/2377-8075-220001053

Copyright: Margaretha Suharsini ${ }^{\circ}$ 2022. This is an open-access article distributed under the terms of the Creative Commons Attribution License, which permits unrestricted use, distribution and reproduction in any medium, provided the original author and source are credited. 
ceptibility for microbial infections to occur, including systemic microbial infections that can be highly life-threatening in immunosuppressed patients. [9] Candida albicansis the main cause of opportunistic microbial infections in patients with cancer. Cancer patients have high risk of fungal infections primarily due to the depression of host immune cells and weakened epithelial barriers induced by chemotherapy.[10]

In normal circumstances, Candida albicans coexists as a fungal commensal with other microorganisms from normal oral flora and does not cause infection. However, changes in the oral and/ or systemic environment can result in imbalance of this species causing infection. Changes in the oral and systemic environment of cancer patients undergoing chemotherapy such as disruption to epithelial barriers and immunosuppression result in overgrowth of Candida thereby facilitating fungal infection.[10] For decades, systemic antifungal drugs have been used to prevent Candida infections. However, due to drug side effects (nausea, vomiting, and diarrhea) and the potential for emergence of resistant strains, systemic antifungal has not been considered to be fully successful. The toxicity and emergence of resistance from antifungal drugs that are currently available are of concern in the health sector, and thus alternative therapies are urgently needed.[11]

Probiotics are defined as living microorganisms, which when given or consumed in sufficient quantities, provide health benefits to the host.[12] Lactobacillus organisms have been used as probiotics for decades and previous studies show evidence of Lactobacillus strains' feasibility to act as alternative biological approaches to combating pathogenic fungi in various human organ systems, including the oral cavity.[13-15] There is no study that shows effects of probiotic on the number of Candida albicansin the oral cavity of children with leukemia who are undergoing chemotherapy. This study was considered as a preliminary study with the aim to investigate the effects of probiotics on the quantitative levels of Candida albicans in the oral cavity of children with leukemia during chemotherapy.

\section{Materials and Methods}

This study was approved by the Dental Research Ethics Committee, Faculty of Dentistry Universitas Indonesia. Clinical experimental study was performed to evaluate the quantitative levels of Candida albicans in the oral cavity through saliva samples.

The subjects were consisted of 11 children with leukemia of ages ranging from 3 to 17 years old who were admitted to Dharmais Cancer Hospital and Kramat 128 Hospital in Jakarta. Patients who had been diagnosed with leukemia by a pediatrician, were entered induction or consolidation phase of chemotherapy, were able to follow instructions for gargling, and had no habitual use of probiotic nor mouthwash met the inclusion criteria. Once the purpose of the study was explained to the parents and guardians, they all signed a document indicating their informed consent. $\mathrm{Pa}-$ tients were instructed to rinse with a bottle of probiotics for 60 seconds, 2 times a day, within 14 days. One bottle of probiotics contained $65 \mathrm{ml}$ liquid at a dose of $6.5 \times 10^{9}$ Lactobacillus casei $\mathrm{CFU} / \mathrm{ml}$.

Oral sample was saliva collected from subjects according to criteria. Saliva samples were taken at baseline that is before rinsing with probiotics, then follow-up registrations and samplings were conducted 7 and 14 days after baseline or rinsing with probiotics. Minimum $2 \mathrm{~mL}$ of non-stimulated saliva was collected in a sterile tube and was immediately cold-transported to the Oral Biology Laboratory Universitas Indonesia. Saliva sample was centrifuged for 5 min with 3000RPM then the supernatant was transferred to another sterile tube and stored at $-80^{\circ} \mathrm{C}$ until used.

Real-time PCR (qPCR) was used for quantification of Candida albicans. Fungal genomic DNA was obtained using Genezol reagent concentration and the concentration and quality of the obtained DNA was determined by by Qubit assay reagents (Invitrogen, Carlsbad, CA). The genomic DNA samples were dissolved in Tris-EDTA(TE) buffer and stored at $-20^{\circ} \mathrm{C}$ until processed. Further, the DNA samples were quantified through a qPCR reaction Candida albicans specific primers (Table 1). For PCR-quantification, each sample was run in duplicate on an ABI StepOnePlus Real-Time PCR System, where a SYBR Green PCR Master Mix (Applied Biosystems, Foster City, CA, USA) was used according to the manufacturer's protocol.

The PCR conditions was set in a final reaction volume of $10 \mu \mathrm{l}$, composed of $50 \mathrm{ng}$ of sample DNA and $1 \mu \mathrm{M}$ of Candida albicans specific primers, with thermal cycling condition consisted of a 10 min initial denaturation at $95^{\circ} \mathrm{C}$, followed by 40 cycles of denaturation at $95^{\circ} \mathrm{C}$ for $15 \mathrm{~s}$, annealing at $60^{\circ} \mathrm{C}$ for $60 \mathrm{~s}$, and elongation at $95^{\circ} \mathrm{C}$ for $15 \mathrm{~s}$. The qPCR product was visualized as melting curve $\left(95^{\circ} \mathrm{C}\right.$ for $15 \mathrm{~s}, 60^{\circ} \mathrm{C}$ for $60 \mathrm{~s}$, and $95^{\circ} \mathrm{C}$ for $15 \mathrm{~s}$ ), and cycle threshold value $(\mathrm{Ct})$ were determined automatically by the qPCR machine.

The estimating amount of Candida albicans genomic DNA was determined by constructing a standard curve with $\mathrm{r} 2$ values for organism tested as shown in Figure 1. To do this, a 5-fold serial dilution of extracted C. albicans(ATCC 10231) was used. The fungus number $(\mathrm{CFU} / \mathrm{ml})$ was assessed by plating culture dilutions on Sabouraud agar, and the same strain was used as positive control while running the qPCR. Therefore, the quantification of Candida albicans from saliva samples was achieved by plotting the Ct values against the log of the respective standard curve.

A comparison of the results was done using SPSS version 20.0. Repeated Measure ANOVA was used to perform statistical analysis to compare the quantification of Candida albicansat baseline, after 7 days, and after 14 days mouth rinsing with probiotics. Pvalue $<0.05$ was considered significant.

\section{Results}

A standard curve was used to determine the number of Candida albicans, while melt curve were used to evaluate the amplicon's specificity using saliva samples (Figure 2).

In this study, the data showed that Candida albicans was presence in all saliva samples. The number or quantification of Candida albicans after converted from its $\mathrm{Ct}$ value into $\mathrm{CFU}$ (colony forming unit) using standard curveis shown in Figure 3. In general, it was observed that in saliva samples of children with leukemia,decreased number of CFU was found sequentially from baseline $(494.363+180.737 \mathrm{CFU} / \mathrm{ml})$, to after 7 days $(276.653+$ $69.903 \mathrm{CFU} / \mathrm{ml})$, and after 14 days $(229.286+50.883 \mathrm{CFU} / \mathrm{ml})$ 
Table 1. Primers used in this study.

\begin{tabular}{|c|c|c|}
\hline Primer name & Sequences & References \\
\hline \multirow{2}{*}{ C.albicans } & Forward:5'-CACGACGGAGTTTCACAAGA -3' & \multirow{2}{*}{25} \\
\cline { 2 - 2 } & Reverse: 5'-CGATGGAAGT'TTGAGGCAAT-3' & \\
\hline
\end{tabular}

Figure 1. Standard curve of Candida albicans.

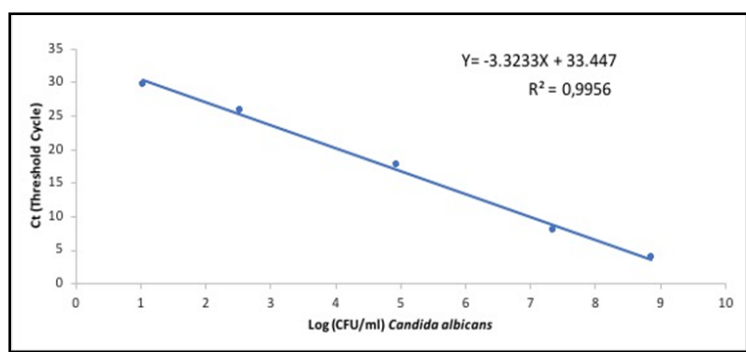

Figure 2. Melt curve profile and melting temperature for Candida albicans.

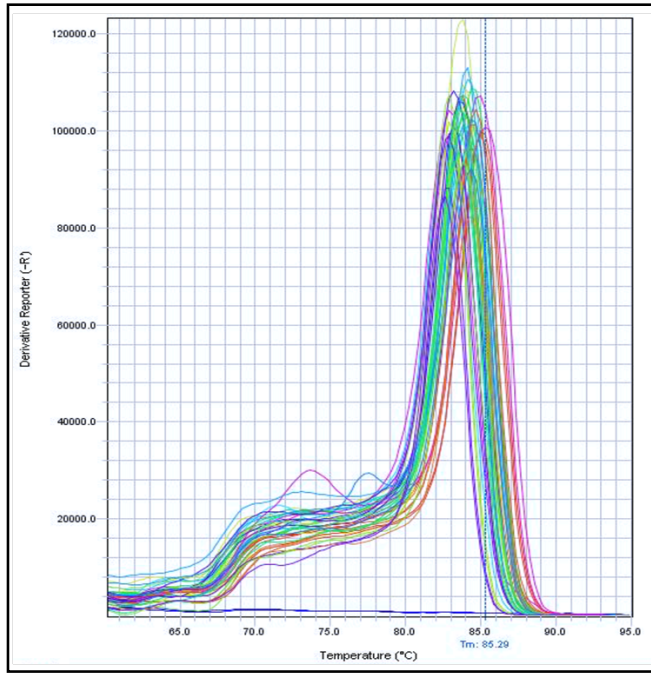

Figure 3. Mean and standard deviation of absolute numbers of Candida albicans (CFU/ml) detected in saliva samples on baseline, 7 days, and 14 days after rinsing with probiotics. ${ }^{*} \mathrm{p}<0.05$.

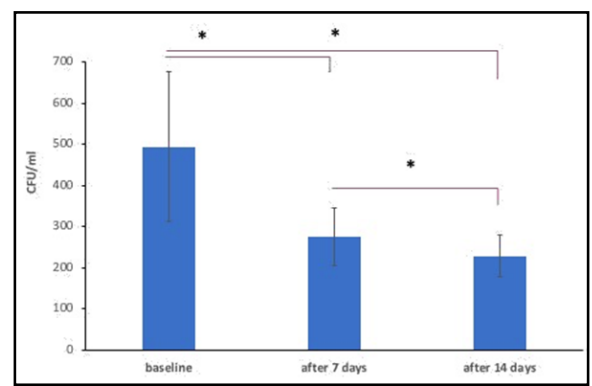

rinsing with probiotics.

Statistically significant differences $(\mathrm{p}<0.05)$ were found between quantities of Candida albicansat baseline and at designated time intervals during and after rinsing with probiotics containing Lactobacillus casei. There were significant differences in the quantities of Candida albicansat every period which are between baseline and after 7 days of rinsing with probiotics $(\mathrm{p}=0.005)$, baseline and after 14 days of rinsing with probiotics $(p=0.002)$, as well as between after 7 days and 14 days of rinsing with probiotics $(\mathrm{p}=0.016)$.

\section{Discussion}

Numerous studies[11, 16-18] have braced up the idea of using probiotics in the battle against oral candidiasis. This study was undertaken to evaluate the relationship between the amount of Candida albicans, the most common pathogen of oral candidiasis, and exposure to probiotic bacteria. Previous studies which also focused on the same issues had mostly been performed in elderly, thus this study focused in another group of immunosuppressed patients that are children with leukemia during the induction and consolidation phase of chemotherapy, as they have increased risk of fungal infection.[10] Candida albicans is present as commensal flora in healthy people and becomes the predominant flora in $60 \%$ of immunosuppresed people.[19] Chemotherapy, especially on children, can lead to severe oral candidiasis which has possibility to spread systematically and become life-threatening, yet there has not been a sufficient evidence of any antifungal drugs that may cure fungal infections in the mouth of people with cancer. 
[20]

In this present study, the major finding was that there was a decrease of the number of Candida albicans in the subjects' saliva following rinsing with probiotics containing Lactobacillus caseiover the course of 14 days. The results within this study is in accordance with results from other studies [15-18], which found that there was significant reduction of Candida cell quantification after probiotics administration. Previous study proved that the consumption of probiotic drink containing Lactobacillus casei was successful in reducing the prevalence of oral Candida and increasing anti-Candida immunoglobulin A levels in healthy individuals. [18] Compatible with this study, the use of bacteria with genus Lactobacillus has been deemed worthy as an alternative method to return disease-inducing microbiota or opportunistic pathogen to a healthy, symbiotic, stable commensal equilibrium.[11]

For the mechanism on how probiotics enhance this well-balanced state, from illness to nutrition, a variety of theories have been suggested, many unproven as yet. Probiotics may compete against pathogenic microorganisms for nutrients and receptors on the cell surfaces, thereby preventing adhesion and colonization of pathogenic microorganisms, such as Candida albicans, on the mucosal surfaces. [21] Furthermore, probiotics were found to work against the main virulence factors of Candida. Probiotics can reduce filamentation and biofilm development in Candida albicans causing candida infection to resolve. [11, 22] By suppressing filamentation, probiotics could assist the host to fight Candida albicans or pathogens more effectively, as the yeast form of Candida albicansis more susceptible to phagocytosis.[11]

Apart from the above, it is worth mentioning that the antimicrobial activity of probiotic bacteria is strain-specific, thus, the clinical application of probiotics should be aimed at specific pathogens and their beneficial effects cannot be generalized. Different microbial probiotic strains could have different effects on the reduction of Candida albicans.[23] For example, one study stated that in a mice model, Lactobacillus rhamnosus was more effective than the Lactobacillus acidophilusin reducing the amount of Candida spp. colonization levels. [24]

Supported by the obtained results in this study, we can approve that probiotics have a protective role in Candida infection, notably colonization. As previously mentioned, it is possible to explain the anti-Candida properties in various way. However, such positive effects are highly associated with the administration method, dosage, the strains of probiotics used, and host factors.

This study has limitations, such as asmall number of sample included due to difficulty in finding subjects within the inclusive criteria and short period of evaluation. We recommend that future studies with larger sample size and longer treatment duration to be undertaken to evaluate the real effectiveness of probiotics treatment in Candida infection.

\section{Conclusion}

This study demonstrated the effects of rinsing with probiotics on the number of Candida albicans on saliva of children with leukemia during the induction and consolidation phase of chemotherapy. A statistically significant reduction on the amount of salivary Can- dida albicans after 7 days and 14 days of rinsing with probiotis was shown. The results of this study suggest that researchers should conduct further studies to investigate the efficacy and long-term effects of using probiotics as antifungal prophylaxis and treatment.

\section{Acknowledgement}

The researcher would like to thank the patients and parents who were willing to take part in this research. The researcher also wants to thank dr. Haridini Intan Setiawati Mahdi, Sp.A(K)Onk, dr. Edi Setiawan Tehuteru, Sp.A(K),MHA, IBCLC, and Prof.drg. Endang Winiati Bachtiar, M.Biomed., Ph.Dfor all the help and guidance that was given. This research was funded by HIBAH PITTA Universitas Indonesia.

\section{References}

[1]. Steliarova-Foucher E, Colombet M, Ries LAG, Moreno F, Dolya A, Bray F, et al. International incidence of childhood cancer, 2001-10: a population-based registry study. Lancet Oncol. 2017 Jun;18(6):719-731.Pubmed PMID: 28410997.

[2]. Gupta S, Howard SC, Hunger SP, Antillon FG, Metzger ML, Israels T, et al. Treating Childhood Cancer in Low- and Middle-Income Countries. In: Gelband H, Jha P, Sankaranarayanan R, Horton S, editors. Cancer: Disease Control Priorities, Third Edition (Volume 3). Washington (DC): The International Bank for Reconstruction and Development / The World Bank; 2015 Nov 1. Pubmed PMID: 26913338.

[3]. Palumbo MO, Kavan P, Miller WH Jr, Panasci L, Assouline S, Johnson N, et al. Systemic cancer therapy: achievements and challenges that lie ahead. Front Pharmacol. 2013 May 7;4:57. Pubmed PMID: 23675348.

[4]. Alam A, Farooq U, Singh R, Dubey VP, Kumar S, Kumari R, et al. Chemotherapy treatment and strategy schemes: A review. Open Access J Toxicol. 2018;2(5):555600.

[5]. Pearce A, Haas M, Viney R, Pearson SA, Haywood P, Brown C, et al. Incidence and severity of self-reported chemotherapy side effects in routine care: A prospective cohort study. PLoS One. 2017 Oct 10;12(10):e0184360. Pubmed PMID: 29016607.

[6]. Chaveli-López B, Bagán-Sebastián JV. Treatment of oral mucositis due to chemotherapy. J Clin Exp Dent. 2016 Apr 1;8(2):e201-9. PMID: 27034762.

[7]. Al Jaouni SK, Al Muhayawi MS, Hussein A, Elfiki I, Al-Raddadi R, Al Muhayawi SM, et al. Effects of Honey on Oral Mucositis among Pediatric Cancer Patients Undergoing Chemo/Radiotherapy Treatment at King Abdulaziz University Hospital in Jeddah, Kingdom of Saudi Arabia. Evid Based Complement Alternat Med. 2017;2017:5861024. Pubmed PMID: 28270852.

[8]. Berger Velten D, Zandonade E, Monteiro de Barros Miotto MH. Prevalence of oral manifestations in children and adolescents with cancer submitted to chemotherapy. BMC Oral Health. 2016 Oct 3;16(1):107. Pubmed PMID: 27716167.

[9]. Al-Ansari S, Zecha JA, Barasch A, de Lange J, Rozema FR, Raber-Durlacher JE. Oral Mucositis Induced By Anticancer Therapies. Curr Oral Health Rep. 2015;2(4):202-211. Pubmed PMID: 26523246.

[10]. Teoh F, Pavelka N. How Chemotherapy Increases the Risk of Systemic Candidiasis in Cancer Patients: Current Paradigm and Future Directions. Pathogens. 2016 Jan 15;5(1):6. Pubmed PMID: 26784236.

[11]. Matsubara VH, Bandara HM, Mayer MP, Samaranayake LP. Probiotics as Antifungals in Mucosal Candidiasis. Clin Infect Dis. 2016 May 1;62(9):1143-53. Pubmed PMID: 26826375.

[12]. Fijan S. Microorganisms with claimed probiotic properties: an overview of recent literature. Int J Environ Res Public Health. 2014 May 5;11(5):474567. Pubmed PMID: 24859749.

[13]. Hu H, Merenstein DJ, Wang C, Hamilton PR, Blackmon ML, Chen H, et al. Impact of eating probiotic yogurt on colonization by Candida species of the oral and vaginal mucosa in HIV-infected and HIV-uninfected women. Mycopathologia. 2013 Oct;176(3-4):175-81.Pubmed PMID: 23925786.

[14]. Coman MM, Verdenelli MC, Cecchini C, Silvi S, Orpianesi C, Boyko N, et al. In vitro evaluation of antimicrobial activity of Lactobacillus rhamnosus IMC 501 $\left(^{\circ}\right)$, Lactobacillus paracasei IMC 502( $\left(^{\circ}\right.$ ) and SYNBIO $\left(^{\odot}\right)$ against pathogens. J Appl Microbiol. 2014 Aug;117(2):518-27. Pubmed PMID: 24836638. 
[15]. Li D, Li Q, Liu C, Lin M, Li X, Xiao X, et al. Efficacy and safety of probiotics in the treatment of Candida-associated stomatitis. Mycoses. 2014 Mar;57(3):141-6. Pubmed PMID: 23952962.

[16]. Ishikawa KH, Mayer MP, Miyazima TY, Matsubara VH, Silva EG, Paula $\mathrm{CR}$, et al. A multispecies probiotic reduces oral Candida colonization in denture wearers. J Prosthodont. 2015 Apr;24(3):194-9. Pubmed PMID: 25143068.

[17]. Kraft-Bodi E, Jørgensen MR, Keller MK, Kragelund C, Twetman S. Effect of Probiotic Bacteria on Oral Candida in Frail Elderly. J Dent Res. 2015 Sep;94(9 Suppl):181S-6S. Pubmed PMID: 26202995.

[18]. Mendonça FH, Santos SS, Faria Ida S, Gonçalves e Silva CR, Jorge AO, Leão MV. Effects of probiotic bacteria on Candida presence and IgA antiCandida in the oral cavity of elderly. Braz Dent J. 2012;23(5):534-8.Pubmed PMID: 23306230.

[19]. Mishra R, Tandon S, Rathore M, Banerjee M. Antimicrobial Efficacy of Probiotic and Herbal Oral Rinses against Candida albicans in Children: A Randomized Clinical Trial. Int J Clin Pediatr Dent. 2016 Jan-Mar;9(1):25-30. Pubmed PMID: 27274151.

[20]. Worthington HV, Clarkson JE, Khalid T, Meyer S, McCabe M. Interventions for treating oral candidiasis for patients with cancer receiving treatment. Cochrane Database Syst Rev. 2010 Jul 7;2010(7):CD001972. Pub- med PMID: 20614427.

[21]. Ujaoney S, Chandra J, Faddoul F, Chane M, Wang J, Taifour L, et al. In vitro effect of over-the-counter probiotics on the ability of Candida albicans to form biofilm on denture strips. J Dent Hyg. 2014 Jun; 88(3):183-9.Pubmed PMID: 24935148.

[22]. Köhler GA, Assefa S, Reid G. Probiotic interference of Lactobacillus rhamnosus GR-1 and Lactobacillus reuteri RC-14 with the opportunistic fungal pathogen Candida albicans. Infect Dis Obstet Gynecol. 2012;2012:636474. Pubmed PMID: 22811591.

[23]. Mundula T, Ricci F, Barbetta B, Baccini M, Amedei A. Effect of Probiotics on Oral Candidiasis: A Systematic Review and Meta-Analysis. Nutrients. 2019 Oct 14;11(10):2449. Pubmed PMID: 31615039.

[24]. Matsubara VH, Silva EG, Paula CR, Ishikawa KH, Nakamae AE. Treatment with probiotics in experimental oral colonization by Candida albicans in murine model (DBA/2). Oral Dis. 2012 Apr;18(3):260-4. Pubmed PMID: 22059932.

[25]. Bachtiar EW, Bachtiar BM. Relationship between Candida albicans and Streptococcus mutans in early childhood caries, evaluated by quantitative PCR. F1000Res. 2018 Oct 16;7:1645. Pubmed PMID: 30450201. 